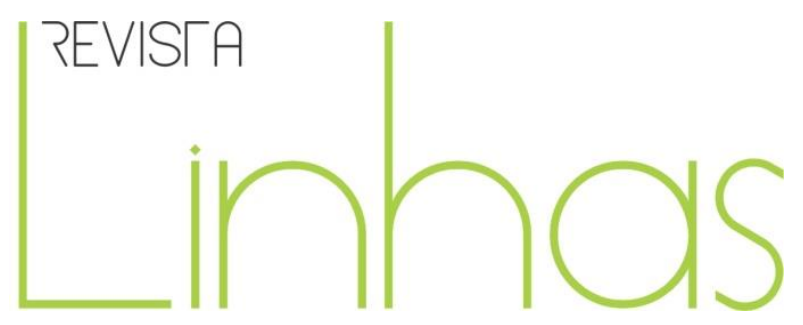

\title{
"Era para já ter te escrito..." A correspondência epistolar entre duas irmãs durante a Ditadura Militar de 1960, no Brasil
}

\begin{abstract}
Resumo
Zelita Rodrigues Correia foi uma das primeiras mulheres a ser presa, em Sergipe, como decorrência da repressão militar contra os estudantes do ensino superior, na década de 1960, no Brasil. Após ser libertada e recém-formada, mudou-se para Salvador, capital da Bahia, onde registrou seu diploma de bacharel em Direito e se inscreveu na Ordem dos Advogados. Nessa cidade, aguardou o desenrolar dos acontecimentos e do processo que lhe foi movido. Durante esse período, por intermédio da escrita epistolar, manteve permanente contato com sua família, em Aracaju. Este estudo tem por objeto uma das cartas enviadas a Zelita por sua irmã, Maria de Lourdes Correia, em 1966. O objetivo foi identificar nessa narrativa algumas tensões e embates nos quais estiveram envolvidos acadêmicos e diretores de faculdades que compunham o ensino superior em Sergipe. A pesquisa fundamentou-se nos pressupostos teórico-metodológicos da História Cultural, a partir dos quais, no âmbito da História da Educação, foi possível o estudo de novos objetos e a utilização de diferentes fontes e abordagens, dentre eles as cartas, a escrita feminina e as representações dos sujeitos. Além das fontes epistolar e bibliográfica, foi utilizada a abordagem da História Oral e a técnica da entrevista, além da análise de conteúdo. Os resultados demonstram que a correspondência trocada possibilita conhecer diversos acontecimentos que fizeram parte desse momento político, em sua relação com o ensino superior. Também evidenciam relações de poder e as sociabilidades vivenciadas entre estudantes da Faculdade de Direito e da Faculdade Católica de Filosofia de Sergipe.
\end{abstract}

Palavras-chave: Brasil - História - 1964-1985; Ensino superior Sergipe; Cartas; Faculdade de Direito de Sergipe; Cultura acadêmica.

\section{Para citar este artigo:}

CRUZ, Marcia Terezinha Jeronimo Oliveira. "Era para já ter te escrito...” A correspondência epistolar entre duas irmãs durante a Ditadura Militar de 1960, no Brasil. Revista Linhas. Florianópolis, v. 16, n. 32, p. 127 149, set./dez. 2015. 


\title{
"It was supposed to have already written to you..." The epistolary correspondence between two sisters during the Military Dictatorship of 1960, in Brazil
}

\begin{abstract}
Zelita Rodrigues Correia was one of the first women to be arrested, in Sergipe, as a result of the military crackdown against students of higher education, in the Decade of 1960, in Brazil. After being released and newly formed, she moved to Salvador, capital of Bahia, where she recorded her Bachelor's degree in law and enrolled at the bar. In this city she waited the unfolding events and the process that was prosecuted to her. During this period, through the epistolary writing, she maintained permanent contact with her family, in Aracaju. This study has as object one of the letters sent to Zelita by her sister Maria de Lourdes Correia, in 1966. The goal was to identify in the narrative some tension and clashes in which were involved academics and directors of faculties that composed the higher education in Sergipe. The research was based on theoretical-methodological assumptions of Cultural history, from which, in the context of the history of education, It was possible the study of new objects and the use of different sources and approaches, including letters, feminine writing and the representations of the subjects. In addition to the epistolary and bibliographic sources; it was used the approach of Oral History and the interview technique, in addition to the content analysis. The results demonstrate that the correspondence makes possible to know many events that were part of this political moment in their relationship with higher education. They also show power relations and the social arrangements experienced between students of the Faculty of law and students of the Catholic Faculty of Philosophy of Sergipe.
\end{abstract}

Keywords: Brazil - History - 1964-1985; Higher education - Sergipe; Letters; Faculty of Law of Sergipe; Academic culture. 


\section{Papel, tinta e representações: a geografia e o lugar das cartas na "escrita de}

si"

Não se sabe ao certo quando a troca de cartas passou a fazer parte do cotidiano humano, apenas que remonta à Antiguidade e que atingiu seu auge entre os séculos XVIII e XIX, na Europa, em decorrência do processo de alfabetização. Os motivos pelos quais as pessoas escrevem e leem cartas podem ser os mais variados. Inegável é que estas se encontram permeadas pelo compartilhamento de vivências pessoais. (Bastos; Cunha; Mignot, 2002).

A escrita das cartas obedece a uma métrica própria relacionada ao espaço/tempo tempo para escrever, tempo para chegar, tempo para ler e refletir sobre o conteúdo, tempo para responder - assim revela as marcas deixadas por quem as escreve a partir do modo particular e singular de ver o mundo e a realidade social (Bastos; Cunha; Mignot, 2002).

Tais movimentos são vistos por Dantas; Freitas (2014), como equivalentes aos de representação e apropriação, conforme proposto por Roger Chartier (1990), na perspectiva da História Cultural. Epístolas podem se constituir em escritos públicos ou privados, dizer respeito a aspectos específicos: amor, família, negócios, além de terem finalidades diversas, a exemplo da religiosa ou política.

Cartas também possuem uma materialidade. Podem ser manuscritas, datilografadas ou digitadas. São compostas por diferentes elementos: papel, tinta, envelope..., que possuem diferentes apresentações e são constituídas em diversos tipos de materiais (Bastos; Cunha; Mignot, 2002).

Todavia, tais correspondências, constituem-se em um exercício quase sempre particular: "geralmente resultam de atividades solitárias, ainda que sua autoria possa ser partilhada por secretários que escrevem ou digitam, por assessores ou por familiares" (DANTAS; FREITAS, 2014, p. 3).

Do ponto de vista linguístico, as cartas se constituem, no entendimento de Marcuschi (2008), em um gênero textual próprio, ligado à vida diária. São padrões sociocomunicativos característicos, integrados por composições funcionais e objetivos 
enunciativos. Seu estilo é resultado da integração de forças históricas, sociais, institucionais e técnicas.

Para Marcuschi os gêneros textuais abarcam diversos setores da vida humana e podem estar representados, por exemplo, em um sermão, discurso acadêmico, conferência, carta pessoal, carta comercial, bilhete, carta eletrônica, bate-papo por computador, aula expositiva, peça judicial, dentre outros (MARCUSCHI, 2008, p. 155).

Como gênero, as cartas possuem sujeitos: emissor/remetente e receptor/destinatário. Sinalizam para o lugar e a data da escrita. Podem conter uma saudação inicial e uma assinatura ao final. Também podem ser apócrifas ou mesmo indicar o uso de um pseudônimo.

Atravessando o tempo, a escrita epistolar muitas vezes guardada e, em alguns casos, escondida em caixas, gavetas, armários, baús e pastas, passou, a partir das últimas décadas do século XX, a ocupar atenção dos pesquisadores: “É cada vez maior o interesse dos leitores por um certo gênero de escritos - uma escrita de si - que abarca diários, correspondências, biografias e autobiografias, independentemente de serem memórias ou entrevistas de história de vida, por exemplo" (GOMES, 2004, p. 7, grifo nosso).

A expressão ou conceito de "escrita de si", como apontam Dantas e Freitas, "foi estabelecido por Foucault (1992), com uma série de estudos sobre "as artes de si mesmo", enfatizando a estética da existência e o governo de si” (DANTAS; FREITAS, 2014, p. 1).

Gomes equipara a escrita de si a uma prática cultural que sempre atraiu mulheres, em especial, o professorado, considerando “[...] que por questões de constrangimento social, tiveram seu espaço de expressão pública vetados, restando-lhes exatamente espaços privados, entre os quais o de uma escrita de si [...]” (GOMES, 2004, p. 9).

Corroborando o entendimento da caracterização da escrita de si como prática cultural e relacionando-a às cartas, Dantas e Freitas afirmam quanto a estas últimas: 
É um objeto material, que demonstra indícios de uma cultura e de um meio, vestígios de práticas sociais de uma época na qual o indivíduo está inserido. As cartas fazem parte de um conjunto de documentos que têm como meta alcançar um destinatário. Elas são suportes da "escrita de si”. (DANTAS; FREITAS, 2014, p. 1, grifo nosso)

Acerca do reconhecimento das cartas como objeto de pesquisa acadêmica, Dauphin e Poublan lembram que "Na historiografia, as cartas ocupam, tradicionalmente, o status de documento" (DAUPHIN; POUBLAN, 2002, p. 75). Contudo, as autoras ressaltam que estas também podem ser objeto de um olhar antropológico:

[...]uma leitura que não visa tanto desvendar a intimidade suposta, mas compreender as razões e a lógica que presidem essas práticas de escritura e de conservação [...] as ferramentas intelectuais podem ser mais ou menos elaboradas, mas a imaginação e a vida emocional são sempre ricas e complexas. [...] (DAUPHIN; POUBLAN, 2002, p. 83).

A respeito do interesse em torno do estudo das cartas, Gomes entende que:

Cartas, diários íntimos e memórias, entre outros, sempre tiveram autores e leitores mas, na última década, no Brasil e no mundo, ganharam um reconhecimento e visibilidade bem maior, tanto no mercado editorial, quanto na academia. A despeito disso, não são ainda numerosos os estudos que se dedicam a uma reflexão sistemática acerca desse tipo de escrito na área da história do Brasil. (GOMES, 2004, p. 8)

Dantas e Freitas seguem nessa direção, ao afirmar: "Os laços existentes entre os meios de comunicação e a História da Educação têm se estreitado cada vez mais e as cartas, como objeto de estudo, vêm ganhando espaço no contexto historiográfico" (DANTAS; FREITAS, 2014, p. 3).

As autoras refletem também acerca das possibilidades investigativas abertas pelo estudo de cartas relativamente às instituições escolares, o que em nossa opinião pode ser ampliado para as de natureza superior-universitária. 
O estudo das cartas em História da Educação chama atenção também para alguns aspectos: a importância dos textos autobiográficos como fonte de pesquisa; a contribuição que estes estudos podem dar, dentre outras formas, para elucidar aspectos específicos de processos de formação; e também, como suporte para perceber elementos das trajetórias de intelectuais, professores e alunos. (DANTAS ; FREITAS, 2014, p. 2)

O entendimento da utilização das cartas para a problematização de determinadas realidades relacionadas ao ensino superior-universitário, baseia-se na concepção de Cruz (2014), que considera a cultura acadêmica como "um tipo particular de cultura, própria de instituições de ensino superior/universitárias, composta por ritos, símbolos e práticas formativas inerentes a um determinado campo acadêmico" (CRUZ, 2014, p. 29).

Para Cruz, a cultura acadêmica pode desvelar práticas culturais havidas entre os membros da academia e destes com a comunidade acadêmica - familiares, amigos, intelectuais, políticos e clérigos - e mesmo com grupos sociais mais amplos que, circunstancialmente, participam de rituais específicos da academia, a exemplo de aulas inaugurais, desfiles públicos, solenidades de formatura. (CRUZ, 2014, p. 326).

A cultura acadêmica teria como uma de suas finalidades realizar a distinção, no espaço social, daqueles que ingressaram/passaram no/pelo ensino superior, relativamente aos demais agentes sociais, por intermédio de atos (ritos) com eficácia simbólica que instituiriam esses agentes como portadores de determinado capital (e poder) simbólico, tornando esses agentes conhecidos e reconhecidos no espaço social. (CRUZ, 2014, p. 326).

A utilização de cartas e, portanto, da escrita de si como elemento por meio do qual seja possível caracterizar alguns componentes da cultura acadêmica de instituições de ensino superior em Sergipe, na década de 1960, assim também de alguns embates e tensões sofridas pela ação de militares em 1966, de modo especial na Faculdade de Direito, é o objetivo deste trabalho.

Para tanto, tem como objeto de análise uma missiva trocada pelas irmãs Zelita Correia e Maria de Lourdes Correia, em 1966, epístola guardada por aproximadamente cinquenta anos pela destinatária, uma das primeiras mulheres a serem presas em Sergipe, 
como estudante oposicionista política ao regime militar. A escolha de referida carta deuse em face das contribuições que pode trazer ao estudo do tema.

Além da carta e das representações nela contidas, este estudo conta com a contribuição de fontes bibliográficas que situam a implantação e organização do ensino superior em Sergipe, a participação feminina, a rede de sociabilidades instituída entre estudantes e professores, assim como destes com diversos segmentos sociais locais. Também há o recurso à entrevista. A análise de conteúdo priorizou o cotejamento entre o texto epistolar, entrevistas com a destinatária e estudos dedicados à ditadura e ao ensino superior em Sergipe.

\section{O ensino superior em Sergipe}

Data do século XIX a primeira iniciativa de fundação de uma instituição de ensino superior em Sergipe, mediante a assinatura de Decreto, em 1860, pelo Imperador D. Pedro II após visita à Província. O Imperial Instituto de Agricultura Sergipano deveria instrumentalizar o desenvolvimento da agricultura. No entanto, a proposta não se concretizou. Não é sabida qual a destinação dada aos recursos destinados à iniciativa (NASCIMENTO, 2006).

Ainda naquele século, precisamente em 1898, houve a tentativa de fundação de uma Academia Jurídica que não passou de mensagem dirigida à Assembleia Legislativa pelo deputado Daniel Campos, presidente da Província, em exercício.

No século $X X$, o desenvolvimento das ciências, a necessidade de crescimento e de obtenção de competitividade econômica, assim como a busca de adequação aos novos padrões de modernidade inspirados pelos ideários republicanos, motivaram, dentre outros, o Presidente da Província, Maurício Graccho Cardoso a fundar o Instituto de Química Industrial (1923) e a Faculdade de Odontologia e Farmácia “Aníbal Bruno” (1925).

A necessidade de que a formação jurídica fosse realizada em Sergipe impulsionou duas diferentes tentativas, uma em 1907, mediante a concessão, pelo Governo do Estado, de subsídio a uma instituição que realizasse esta formação e para o qual não surgiram interessados e, em 1925, por intermédio da fundação de uma sociedade civil privada, 
denominada de Faculdade Livre de Direito "Tobias Barretto", composta por juristas ligados ao Poder Judiciário, Executivo e Legislativo (CRUZ, 2014).

Esta última ideia recebeu vigoroso apoio governamental que entendia que a formação jurídica contribuiria para capacitar os próprios quadros do executivo local. Entretanto, não houve interessados em se matricular na instituição, possivelmente, dentre outros motivos, por não haver a necessidade de formação superior para o exercício da advocacia.

A Igreja Católica deu os primeiros passos no sentido de realizar a formação superior, mediante a formação de padres realizada pelo Seminário Diocesano, no período de 1913 a 1934, quando o curso foi extinto pela Santa Sé.

Assim, apenas após a redemocratização política ocorrida no final da década de 1940 e quando o país e o estado vivenciavam momentos de franco crescimento com a implantação, expansão e interiorização da educação, dos transportes e da comunicação, ressurge o projeto de implantação do ensino superior em Sergipe pelas mãos do então governador José Rollemberg Leite.

Nos idos de 1948, foram fundadas a Escola Superior de Química e a Faculdade de Ciências Econômicas, instituições mantidas pelo Governo do Estado de Sergipe. Em 1950, a partir da reunião de diversos juristas e intelectuais, foi fundada a Faculdade de Direito de Sergipe, com natureza jurídica de sociedade civil privada.

Também foi constituída, pela Igreja Católica, a Faculdade de Filosofia, que, posteriormente, instituiria a Escola de Serviço Social de Sergipe (OLIVEIRA, 2011). Por fim, no início da década de 1960, foi fundada a Faculdade de Medicina de Sergipe, após uma década de negociações para sua constituição como uma sociedade civil.

Bretas (2010) aponta que os diversos e divergentes interesses que constituíram o ensino superior em Sergipe do final da década de 1940 ao início da década de 1960, possivelmente interferiram no processo de formação de uma comunidade científica, vez que as instituições e seus professores encontravam-se em diferentes patamares no tocante à produção do conhecimento, assim como atribuíam finalidades específicas, nem sempre propriamente científicas, para a formação que era propiciada aos jovens. 
Por outro lado, estas instituições superiores em Sergipe haviam capitalizado parcela da juventude secundarista que já possuía experiência de mobilização política a partir da vivência nos grêmios escolares de diversas instituições da capital, como o do Colégio Estadual de Sergipe. Um núcleo estudantil que se organizava.

A organização política da sociedade civil em torno do avanço dos direitos sociais, a crise institucional e política, a interferência do capitalismo internacional, conviviam com o processo de expansão/sistematização do ensino superior, gestado pelo governo federal.

Em Sergipe, a Faculdade de Direito foi a única a ser federalizada, em 1960. Posteriormente, todas as instituições superiores foram reunidas em um tumultuado processo que deu origem, em 1967, à Universidade Federal de Sergipe.

Foi neste complexo e mutante cenário que permou a vida dos estudantes entre o final das décadas de 1950 e de 1960, em Sergipe, no qual Zelita e Maria de Lourdes Correia ingressaram, cursaram e concluíram sua formação superior.

Mesmo com mudanças ocorrendo simultânea e ininterruptamente, em 1960, Sergipe era, ainda, "um Estado predominantemente rural, com um percentual de 61,8\% dos seus habitantes vivendo no campo ou em aglomerados não urbanos. [...]" (DANTAS, 2004, p. 153). Consequentemente, a formação superior feminina era reduzida.

Cruz (2012a) apurou, a partir do exame dos registros de nascimento, casamento, declarações, entre outros documentos, que em cursos de humanidades (Letras e Serviço Social) o percentual de mulheres oscilava entre 80 e $90 \%$ dos estudantes. Em cursos ligados ao mercado de trabalho (Química e Economia/Ciências Contábeis) esta relação se invertia, explicada pelo momento econômico vivido no Brasil. Em cursos elitizados, como Medicina e Direito, as mulheres mantiveram uma média de 1/3 das matrículas (CRUZ, 2012a, p. 3).

\section{Destinatária e remetente: estudantes em Sergipe na década de 1960}

Zelita Rodrigues Correia nasceu na década de 1940, em Aracaju, Sergipe. Seu núcleo familiar era composto por pai, mãe e seis filhos. O pai, que servira ao exército por algum tempo, dedicava-se então ao comércio e a família morava na casa localizada nos 
fundos do estabelecimento, situado no centro da cidade. A mãe cuidava do lar e da educação dos filhos, que seguiram formações e carreiras diversas.

O irmão mais velho de Zelita, Gerson Rodrigues Correia, obtivera o título de bacharel na Faculdade de Direito da Bahia, na década de 1950, quando o ensino superior e a formação jurídica começavam a ser efetivamente implantados em Sergipe.

Na Bahia, estudara com o também sergipano Luís Rabelo Leite, estabelecendo laços de amizade. Após tornar-se bacharel, Gerson Correia fixou residência em Salvador, passando a atuar como advogado. Convolou núpcias e continuou a morar na capital baiana.

Zelita estudou em escolas públicas da capital de Sergipe e concluiu o curso colegial no Colégio Estadual de Sergipe, em 1960, onde teve a oportunidade de conviver com professores da Faculdade de Direito que também ali atuavam, a exemplo do Dr. Gonçalo Rollemberg Leite e Dr. Manoel Cabral Machado.

Foi aprovada, em 1961, no Exame de Habilitação para ingresso na Faculdade de Direito de Sergipe, juntamente com treze outros estudantes, dentre eles, Olavo Ferreira Leite Filho, filho de um dos professores fundadores da Faculdade e Leandro Ribeiro de S. Maciel, pertencente a uma tradicional família de políticos locais. No grupo, havia apenas duas mulheres: Zelita e Maria Luiza Cruz, as mais jovens da turma.

Outro membro da família de Zelita era Maria de Lourdes, a irmã mais jovem que optou pela formação docente em línguas vernáculas, realizando seus estudos na Faculdade Católica de Filosofia. As irmãs tiveram educação religiosa cristã e integraram a Juventude Universitária Católica (JUC). Zelita, mais tarde, integrou a Ação Popular (AP).

Como aponta Cruz (2012b) ao estudar as mulheres sergipanas que militaram na esquerda estudantil na década de 1960, Zelita Correia concedia um sentido diferenciado para o ensino superior, se consideradas algumas "marcas sociais" relativas às mulheres de então.

[...] Segundo Santos, os estudantes achavam que elas iam "para lá [Faculdade de Direito de Sergipe] procurar marido, por conta disso, logo no primeiro ano começávamos a brigar por nota e prontamente eles percebiam que não era bem para procurar marido que estávamos ali." Ela destacou que havia estudantes muito competentes também em 
outros cursos como química e economia. Mas como estes cursos eram noturnos, a presença feminina era menos preponderante. (SANTOS, 2011)'. [...] (CRUZ, 2012b, p. 5)

Nos anos em que estudou na Faculdade de Direito, além de competir com os demais colegas homens, no tocante às notas, Zelita Correia participou intensamente do movimento estudantil: fez parte da Sociedade Santo Ivo, que prestava assistência aos internos do Reformatório Penal de Aracaju. Foi coordenadora do Movimento de Cultura Popular em Sergipe (MCP). Foi simpatizante do Partido Comunista do Brasil (PCB).

Em 1964, poucos meses após o golpe militar, foi presa juntamente com outras mulheres e processada em Inquérito Policial Militar movido contra participantes da Campanha Nacional de Alfabetização (CNA), que utilizava o método Paulo Freire.

A prisão se deu na manhã do dia 13 de maio de 1964, quando Zelita estava na aula do professor processualista Dr. Balduíno Ramalho. Segundo Correia (2014), o então Tenente Rabelo, juntamente com outro oficial do Exército foi até a Faculdade de Direito e na porta da instituição solicitou ao Bedel, "seu João", que a informasse acerca do "convite" para que ela os acompanhasse.

Em um jipe do Exército, foi levada até a casa de seus pais. Pressentindo que poderia ser presa a qualquer momento, diante de sua atuação política, mantinha uma mala pronta, escondida embaixo de sua cama. Ao sair de casa acompanhada pelos oficiais do Exército, deixou os pais aos prantos. Chegou ao quartel do $28^{\circ}$ Batalhão de Caçadores, em meados daquela tarde. Na manhã seguinte, somavam-se oito presas.

Segundo Dantas (1997, p. 99), a prisão, em 1964, das primeiras mulheres envolvidas com a resistência ao regime militar em Sergipe causou grande clamor público, o que foi evitado pelas autoridades castrenses após a edição do Ato Institucional $n^{\circ} 5$.

\footnotetext{
${ }^{1}$ Zelita Rodrigues Correia dos Santos foi o nome que a entrevistada passou a adotar a partir do casamento, ocorrido em 1971. Neste artigo optamos pelo nome civil utilizado pela entrevistada ao tempo do recebimento da epistola que se constituiu em objeto/fonte de estudo.
} 


\section{Pelos trilhos da Leste: o encontro de signatárias...}

"[...] eu estava deixando saber o resultado de algumas conversas por aqui. [...] vamos tratar de outros assuntos, que aliás, são muitos hoje. Abundam." (CORREIA, 1966)

Após ficar presa por cinquenta e dois dias na Enfermaria do Quartel do $28^{\circ}$ Batalhão de Caçadores, em Aracaju e, de haver prestado depoimento às autoridades castrenses, Zelita Correia foi uma das últimas mulheres a ser solta. Retornou às atividades estudantis e concluiu as disciplinas do curso, obtendo o grau de bacharel em Direito em 08 de dezembro de 1965 .

Entrementes, a "caça” aos estudantes do ensino superior ligados ao movimento estudantil e aos partidos políticos de esquerda continuava. Na Faculdade de Direito não foi diferente e o diretor, à época, Procurador de Justiça do estado de Sergipe, foi instado a indiciar criminalmente os estudantes, do ensino superior sergipano, envolvidos.

Foi um período tenso e, segundo Correia (2012; 2014), a atitude do diretor Dr. Gonçalo Rollemberg Leite não foi compreendida por muitos estudantes àquela época, mas que ela de modo particular, anos após, vislumbrou que ele tivera um sábio posicionamento diante do que as circunstâncias lhe impingiam:

[...] Luís Eduardo Costa que era da Faculdade de Economia me dizia assim: 'mas, Zequinha (era meu nome, codinome: Zequinha), ele aceitou denunciar a gente'. Aceitou. Doutor Gonçalo era Procurador de Justiça, aceitou a denúncia contra nós. Dudu Cabral [Eduardo Cabral Menezes, ex-aluno da FDS] se recusou, era o Subprocurador. Mas, olhando para trás, tinham outras coisas para preservar lá na Faculdade de Direito, tinha o mandato do doutor Bonifácio que todo mundo sabia que era um esquerdista. Tinha o mandato do doutor Osman, tinha Antônio Góis... [...]" (CORREIA, 2012; 2013, grifos nossos)

O parecer apresentado pelo Dr. Gonçalo Rollemberg Leite, atribuindo à Justiça Militar a competência para processar os acusados possibilitou, inclusive, que os ocupantes de cargos públicos não fossem imediatamente demitidos a bem do serviço público (Correia, 2014). 
Convém ressaltar que, à época, ainda não havia sido editada a "Lei de Segurança Nacional” e que não existia, então, qualquer tipificação legal penal ou penal militar específica para as atitudes julgadas como de "ordem subversiva" ou "subversiva da ordem".

Zelita, após a soltura, também deu sequência ao trabalho na Secretaria Estadual de Educação, onde era funcionária concursada, passando a realizar serviço de assessoria, considerando o fim das atividades da CNA. Segundo Dantas:

A Campanha Nacional de Alfabetização e o Movimento de Cultura Popular, vinculados à Secretaria de Educação, foram prontamente extintos. Diversos dos seus integrantes foram presos e alguns processados. Também perderam a liberdade alguns participantes do Método Paulo Freire, e cerca de uns vinte professores passaram a responder Inquérito Policial Militar. (DANTAS, s. d., p. 10)

Como reflexo da nova configuração política, o então Secretário da Educação e, amigo do irmão de Zelita Correia, Dr. Luis Rabelo Leite, deixou o cargo. Em seu lugar, assumiu o Dr. Manuel Cabral Machado, um dos fundadores da Faculdade de Direito de Sergipe e ex-professor de Zelita no Colégio Estadual de Sergipe e na Faculdade de Direito.

De acordo com Correia (2014), na administração do Dr. Manuel Cabral Machado frente à pasta de Educação, suas atividades, como funcionária, consistiram em realizar a triagem e organização de correspondências, em instruir processos relativos aos requerimentos funcionais.

Atuou nesse mister até que, ao se identificar em uma ligação telefônica, foi reconhecida por uma diretora de escola que a denunciou imediatamente ao Comandante do $28^{\circ}$ Batalhão de Caçadores, sob a alegação de que por haver sido presa e ser considerada subversiva, jamais poderia estar realizando atividades nas quais tinha acesso a documentos e informações. De imediato, o comandante contatou o Secretário de Educação, a exigir-lhe explicações. O clima era propício à ação de delatores, como informou Dantas: 
Eram políticos interessados em tirar vantagem da situação, militares reformados identificados com as ações direitistas, funcionários arrivistas na busca da ascensão fácil, alguns estudantes e cidadãos comuns que julgavam praticar atos de patriotismo. Sem falar naqueles que dantes passavam por esquerdistas e viraram colaboradores dos militares, geralmente de forma sorrateira. (DANTAS, s. d., p. 5)

Já não havia como sustentar a presença de Zelita Correia na instituição. Fora exposta e a situação política pedia prudência. Com a colaboração do Dr. Manuel Cabral Machado, obteve licença não remunerada para trato de interesse pessoal e seguiu para Salvador. Aguardou na capital baiana o desenrolar dos fatos e o processamento do Inquérito Policial Militar. Buscou condições para o exercício da advocacia. Precisava reconhecer o diploma obtido na Faculdade de Direito de Sergipe e inscrever-se na Ordem dos Advogados do Brasil, Seccional Bahia. Para tanto, eram exigidos atestados e certidões:

[...] Gama ficou também de escrever para você essa semana [...] veio aqui sábado passado e veio ontem. Veio dizer que havia conversado com um delegado que é amigo dele e que este havia sondado sobre a situação de sua fôlha corrida e o môço disse que é melhor por enquanto não se mexer nisso, porque os que estiveram implicados só vão receber com seis meses (Gil não levou fôlha corrida não) e que há pouco em fevereiro, Viana e Zé Rosa foram presos aqui e até levados aí para a Bahia; que o negócio ainda está quente e que é melhor não mexer muito porque êles estão esquecidos de você (dr. Aloísio disse que tudo está arquivado) mas, mexendo, êles podem ficar com você em vista. (CORREIA, 1966, p. 4 e 5 , grifos nossos)

Em Salvador, Zelita foi morar com sua irmã mais velha, Norma Correia Marinho, com a qual permaneceu até 1967, quando esta veio a falecer. A partir de então, Zelita Correia passou a morar com seu irmão Gerson Correia, sua cunhada e sobrinha.

Sem ter como se sustentar, com pouca experiência em advocacia e nenhum cliente, auxiliava seu irmão no escritório de advocacia, mas, ainda assim dependia da ajuda dos pais que semanalmente, por meio ferroviário, enviavam-Ihe suprimentos e dinheiro para o consumo de cigarros, seu hábito compulsivo. 
Juntamente com esta encomenda e, a partir do auxílio de funcionários da companhia de trens Leste Brasileira, cujo sindicato de trabalhadores era dos mais antigos e combativos de Sergipe (Dantas, s. d, p. 2), cartas eram trocadas com a irmã Maria de Lourdes, sem que tal correspondência epistolar tenha sido detectada ou censurada pelas autoridades castrenses, que se saiba.

\section{O que dizia(m) a(s) carta(s) sobre a ação militar em Sergipe?}

Zelita Correia não soube informar quantas cartas trocou com sua irmã durante o período em que esteve em Salvador, nem quantificou as cartas que foram por ela guardadas. Recordou-se que, às vezes, as missivas chegaram a ser semanais e, em alguns períodos, eram rarefeitas.

Maria de Lourdes mantinha o exercício da correspondência epistolar não apenas pelo laço fraternal ou proximidade ideológica com a irmã, mas, também, porque sua escrita e leitura eram os veículos que possibilitavam, diante da distância, o contato entre Zelita, sua mãe e amigos.

As cartas, não continham apenas a intencionalidade de situar Zelita quanto à situação política em Sergipe ou mesmo o discurso de uma única pessoa, na medida em que tratavam, conjuntamente, dos mais variados assuntos e temas do cotidiano familiar e da juventude sergipana que compunha o ensino superior de então, como também das sociabilidades que vivenciavam.

Talvez por isso, Zelita Correia tenha guardado por quase cinquenta anos a carta que lhe foi escrita em 18 de março de 1966 e que continha, em seu bojo, representações enfáticas sobre o momento político vivenciado em Sergipe naquele mês de 1966. Da resistência às investidas dos militares, tema candente de então e que lhe marcou por toda vida.

Com seis páginas manuscritas à tinta, por intermédio de caneta esferográfica, na cor azul, a carta encadeava temas distintos: família, amigos, colegas de faculdade, ordem doméstica, dentre outros. Apresentava a interação entre estudantes e professores, assim 
como, premiação na Faculdade Católica de Filosofia de Sergipe, conforme constante do excerto a seguir:

Minhas aulas tiveram início no dia 7 deste, Benza Deus, parece que este ano eu comecei com o pé direito. O padre já me fez dois rasgados elogios de público, só você vendo, está me promovendo às pampas. Gostou muito de minha prova de Teologia, me deu nove. E segue por ai. Também M. Jacques me deu um prêmio por ter sido a melhor aluna de Francês do $1^{\circ}$ ano - ano passado. Foi um livro de francês muito bacana. Como vê fecho. (CORREIA, 1966, p. 1 e 2, grifo nosso)

O "padre" referido por Maria de Lourdes era o Bispo Auxiliar Dom Luciano José Cabral Duarte, que esteve à frente da fundação da Faculdade Católica de Filosofia e era seu diretor, além de conselheiro espiritual da Juventude Católica Universitária em Sergipe. Com doutoramento na Universidade de Sorbonne, "Dom Luciano" foi a autoridade a quem os militares depositaram a responsabilidade de conduzir o processo de fundação da Universidade Federal de Sergipe.

Os rituais de ingresso no ensino superior, de modo geral, também foram apontados. Quanto a estes temas, Cruz (2012a) e Cruz (2014), em suas pesquisas acerca do movimento estudantil e da Faculdade de Direito de Sergipe, com base em fontes orais e publicações da imprensa periódica, enfatizaram, considerando o período político restritivo, que de um lado eram realizados protestos estudantis velados e, de outro, a ação dos estudantes era acompanhada de perto pelos órgãos de vigilância do regime de exceção.

Como o trote sempre foi uma típica interação estudantil, mesmo neste cenário, incorporava a irreverência, ainda que contida.

Dinah passou [a referir-se ao exame para ingresso na Faculdade Católica de Filosofia]. E no trote eu mandei parar no Cacique para Dinah fazer uma saudação a Freitas [responsável pelo estabelecimento, que era conhecido popularmente como alguém "sovina"]. Fui com Denise buscálo lá dentro e ele veio abrindo os braços e dizendo: "Dinah minha filha, o que é que vc quer?" e foi buscar conhaque Dreher e sanduiches de queijo. Não é de pasmar? Se vc ainda não sabe, a palhoça do Cacique foi derrubada, é uma pena. Liginha, irmã de Chico Leite Neto também 
passou em História. No trote ela saiu perto de uma menina quase tão pequena quanto ela com um brinquedo na mão e com um cartaz chamando para brincar de cirandinha. (CORREIA, p. 2, grifos nossos)

Na parte final do excerto acima, é possível verificar a rede de sociabilidades entre os estudantes e autoridades. O restaurante "Cacique Chá" foi o lugar de encontro dos intelectuais e políticos sergipanos, nas décadas de 1950 e 1960. A "palhoça”, uma puxada coberta com palhas, que se situava ao lado do "Cacique", sua extensão, que era frequentada pelos estudantes, enquanto os intelectuais frequentavam o lado de dentro do estabelecimento.

“Chico Leite Neto" era, em verdade, o filho do Senador Francisco Leite Neto, um dos professores fundadores da Faculdade de Direito de Sergipe, falecido em 1964, irmão de Gonçalo Rollemberg Leite, Procurador de Justiça do Estado e diretor da Faculdade de Direito.

Em outro momento, a narrativa da carta dá destaque ao que parece ser o maior interesse de Zelita Correia: a Faculdade de Direito, os colegas e os professores que lá deixara. Maria de Lourdes começa por ressaltar a ausência de funcionamento da instituição: "As aulas da sua ex-faculdade ainda não começaram porque os professores fizeram greve por causa do dinheiro que há cinco anos não recebem" (CORREIA, 1966, p. 2).

Todavia, Cruz (2014) não detectou qualquer inscrição na documentação da Faculdade de Direito que confirmasse a greve apontada por Maria de Lourdes Correia, mesmo que tenha sido possível verificar que o processo de federalização iniciado em 1960 ainda estivesse em andamento e que os funcionários (administrativos ou docentes) ainda não recebessem seus vencimentos como servidores públicos federais.

A quantidade de capital simbólico e capital social dos professores da Faculdade de Direito, em especial, do diretor da instituição, o jurista Gonçalo Rollemberg Leite, estão caracterizados no excerto a seguir, no qual Maria de Lourdes os nomina por "calma e moral costumeira": 
[...] Sim, hoje de tarde foi o trote de lá [Faculdade de Direito]. Eu fui olhar, estava engraçado mas quase dá galho, senão repare: Abelardo que passou no vestibular (Direito) chegou lá na faculdade [Faculdade Católica de Filosofia] hoje dizendo que Direito estava cercada de policiais. Hoje depois do trote, eu soube direito como foi. Os policiais (cerca de 60) invadiram a faculdade e o Gonçalo [a referir-se ao diretor, Dr. Gonçalo Rollemberg Leite] na sua calma e moral costumeira, pô-los para fora a chamá-los de "canalhas!" e coisas que tais. Depois, atente bem para o detalhe, chamou a comissão de trote, mandou comprar bomba e foguete pros meninos soltar e cachaça pros meninos beber. Um detalhe importantíssimo: saiu acompanhando o trote pela rua e na esquina da Moda eu o ouvi dizer: "os bêbados estão ótimos". Saíram umas piadas horríveis com o padre. (CORREIA, 1966, p. 2 e 3, grifos nossos)

Para Bourdieu (2009), o capital simbólico pode ser entendido como o volume de poder simbólico detido por determinado agente. O poder simbólico é concebido pelo autor como "o poder de construção da realidade que tende a estabelecer uma ordem gneseológica, o sentido imediato do mundo [...]” (BOURDIEU, 2009, p. 9). É “a forma transformada, quer dizer, irreconhecível, transfigurada e legitimada, das outras formas de poder." (BOURDIEU, 2009, p. 15). Por sua vez, para o autor, o capital social é considerado:

[...] o conjunto de recursos atuais ou potenciais que estão ligados à posse de uma rede durável de relações mais ou menos institucionalizadas de interconhecimento e de inter-relacionamento ou em outros termos, à vinculação a um grupo, como conjunto e agentes que não somente são dotados de propriedades comuns (passíveis de serem percebidas pelo observador, pelos outros e por eles mesmos), mas também são unidos por relações permanentes e úteis [...]" (BOURDIEU, 2008b, p. 67)

Estes capitais não são quantificáveis economicamente, embora a sua base seja de natureza econômica. Na passagem aludida na carta, a elevada quantidade desses capitais, advinda do fato da família Leite ter origem na aristocracia agro-açucareira e atuação política destacada em Sergipe, pode ser uma das justificativas, senão a justificativa, para que a ação do diretor Gonçalo Rollemberg Leite não tivesse Ihe trazido complicações. Apenas um agente com significativa quantidade desses capitais teria sido capaz, como o foi, de enfrentar as autoridades castrenses e proteger os alunos contra possíveis investidas durante o trote. 
Ainda quanto ao trote, foi possível identificar as representações de Maria de Lourdes relativas aos estudantes do ensino superior em Sergipe, evidenciadas no trecho a seguir, a partir de expressões ambivalentes como Direito / são o "fino". Química / "primou pela grossura". Também apresenta elementos caracterizadores do trote estudantil, como a preponderância masculina e a realização de troças masculinizadas, além da utilização de bebida alcoólica.

Os calouros de Direito este ano são o "fino". Repare tem 4 ou 5 meninas e dentre outros estão: João Gama, Abelardo, Mário Jorge, Wellington, Benedito, o irmão de Arara e outros que eu me esqueço. Tava tudo bêbado hoje. Chico ( $2^{\circ}$ ano) foi da Comissão de trote de Química desse ano que vê-se logo, primou pela grossura. Uma amostra: mulher de boi é vaca? Outra: ovos está tão caro, tão caro, que para se obter uma dúzia tem que se juntar a riqueza de 6 homens. Não sei outras pq dormi e não assisti. (CORREIA, 1996, p. 4, grifos nossos)

Segundo Bourdieu (2008a), é da essência dos rituais consagrar a diferença. Deste modo, "ritos diferenciados sexualmente consagram a diferença entre os sexos, constituem em distinção legítima, uma simples diferença de fato" (BOURDIEU, 2008a, p. 98-99).

É importante ressaltar que os estudantes apontados por Maria de Lourdes no excerto acima, com apenas uma exceção, comporão um núcleo de resistência ao regime militar em Sergipe. Serão presos e processados, alguns torturados. Perderão os direitos políticos estudantis no final da década de 1960, estratégia engendrada pelo Reitor da Universidade Federal de Sergipe para que pudessem concluir seus cursos (Cruz, 2014). Estes estudantes, em sua maioria, após a redemocratização, ocuparão cargos eletivos no Poder Legislativo, assim como, funções e cargos no Executivo e no Judiciário do estado de Sergipe (Cruz, 2012b).

Uma vez em Salvador, só restava a Zelita Correia esperar o tempo certo para retornar a sua terra natal. Parece ter seguido o que Ihe recomendou Maria de Lourdes: “[...] De forma, minha nêga, que eu acho que o melhor mesmo é ter um pouco mais de paciência; e esperar aí se possível. Se você vir que a coisa aí não está boa, se continua como eu deixei, venha esperar aqui, está na tua casa" (CORREIA, 1966, p. 6, grifo nosso). 
E foi exatamente em Salvador que Zelita Correia deu sequência à sua carreira jurídica. O longo interregno de tempo para envio dos processos do $28^{\circ}$ Batalhão de Caçadores situado em Aracaju, para a $6^{\text {a }}$ Região Militar sediada em Salvador, possibilitou que Zelita reconhecesse seu diploma, obtivesse os atestados e certidões. Ingressou na Ordem dos Advogados do Brasil na Bahia, graças à ação de seu presidente Dr. Álvaro Peçanha Martins que afastou a necessidade de apresentação da Folha de Antecedentes Policiais para a inscrição naquela seccional. A esse respeito, Zelita Correia declarou:

[...] A gente só apresentava Folha Corrida do Cartório de Distribuição da Justiça estadual. Como a Justiça Militar era federal, não entrava no jogo. Era assim que os juristas de verdade "passavam a perna" nas leis de exceção. Foi desta maneira que o Dr. Gonçalo conseguiu que João Augusto Gama e outros meninos: Wellington Mangueira, Mário Jorge Vieira..., conseguissem fazer vestibular' ${ }^{2}$. Mas a OAB/SE exigia o tal atestado. (CORREIA, 2014, grifo nosso)

Também foi em Salvador que Zelita Correia prestou concurso público e foi aprovada para exercer o cargo de Promotora de Justiça.

Apesar de o Inquérito Policial Militar ter sido inicialmente arquivado pela ausência de provas e de tipificação legal, após o advento da Lei de Segurança Nacional, que criou tipos penais específicos relacionados à subversão da ordem, o processo foi desarquivado e reaberto.

\section{Considerações finais}

Litinha, não pense que nós aqui estamos dormindo, não estamos nos interessando não. Pelo contrário, nós vamos a um, a outro, nos preocupamos bastante. Resta-nos pedir a Deus um pouco + de paciência. (CORREIA, 1966, p. 6)

\footnotetext{
${ }^{2}$ A respeito desse fato, ver o esclarecedor depoimento de Wellington Dantas Mangueira Marques, em Cruz (2014, p. 202).
} 
Como afirmaram Dantas e Freitas (2014, p. 3), "Carta é laço, une uma presença a uma ausência. É ponte, proporciona encontros." Esta característica pode ser atribuída à correspondência epistolar mantida entre Zelita Correia e sua irmã Maria de Lourdes.

As missivas, durante o período do afastamento de Aracaju em razão da atuação na resistência ao regime militar em Sergipe, possibilitaram não apenas manter a relação emocional e afetiva entre Zelita Correia e seus familiares como também registrar alguns elementos e circunstâncias da ação militar em Sergipe no ano de 1966, relativamente ao ensino superior.

A carta destinada a Zelita Correia mostrou, conforme apontado por Dauphin e Poublan (2002), Dantas e Freitas (2014) e Cruz (2014), algumas possibilidades investigativas no âmbito da História, da História da Educação e da cultura acadêmica. Foi, ao seu turno, fonte e objeto de análise. Documento e prática vistos sob o olhar históricoantropológico.

Por intermédio da missiva, foi possível identificar práticas e rituais vivenciados por estudantes da Faculdade Católica de Filosofia e Faculdade de Direito de Sergipe, evidenciando elementos de sua cultura acadêmica.

\section{Referências}

BASTOS, Maria Helena; CUNHA, Maria Teresa Santos; MIGNOT, Ana Chrystina Venâncio. Laços de Papel. In: BASTOS, Maria Helena; CUNHA, Maria Teresa Santos; MIGNOT, Ana Chrystina Venâncio. Destino das letras: história, educação e escrita epistolar. Passo Fundo (RS): Editora da UPF, 2002. p. 05-09.

BOURDIEU, Pierre. A economia das trocas linguísticas: o que falar quer dizer. Tradução Sérgio Miceli. Mary Amazonas Leite de barros, Afrânio Catani, Denice Bárbara Catani. Paula Monteiro e José Carlos Durand. São Paulo: Edusp, 2008a.

BOURDIEU, Pierre. O capital social - notas provisórias. In: NOGUEIRA, Maria Alice; CATANI, Afrânio (Orgs.). Escritos da educação. 10. ed. Petrópolis, RJ: Vozes, 2008b. p. 65-70. 
BOURDIEU, Pierre. O poder simbólico. Tradução de Fernando Tomaz. Rio de Janeiro: Bertrand Brasil, 2009.

BRETAS, Silvana Aparecida. A política de federalização dos estabelecimentos de ensinos e a criação da Universidade Federal de Sergipe (1950-1970): uma contribuição ao debate histórico. 2009. Disponível em:

<http://www.sbhe.org.br/novo/congressos/cbhe5/trabalho_completo.php?id=828>. Acesso em: 23 fev. 2010.

CHARTIER, Roger. A história cultural: entre práticas e representações. Rio de Janeiro: Bertrand Brasil, 1990.

CORREIA, Zelita Rodrigues. Carta recebida de Maria de Lourdes Correia. Aracaju: Sergipe, 1966.

CORREIA, Zelita Rodrigues. Depoimento concedido à Marcia Terezinha Jerônimo Oliveira, em dezembro de 2012, Aracaju: Sergipe.

CORREIA, Zelita Rodrigues. Depoimento concedido à Marcia Terezinha Jerônimo Oliveira, em fevereiro de 2013, Aracaju: Sergipe.

CORREIA, Zelita Rodrigues. Depoimento concedido à Marcia Terezinha Jerônimo Oliveira, em julho de 2014, Aracaju: Sergipe.

CRUZ, José Vieira. Da autonomia à resistência democrática: movimento estudantil, ensino superior e a sociedade em Sergipe, 1950-1985. Salvador: UFBA, 2012a. Tese (Doutorado em História).

CRUZ, José Vieira. Entre o movimento estudantil e a luta pela igualdade de direitos para as mulheres: uma contribuição à memória da militância feminina em Aracaju/SE, 19601988. In: ENCONTRO NACIONAL DE HISTÓRIA ORAL, XI, Rio de Janeiro, 2012. . Anais ... Rio de Janeiro: UFRJ, 2012b.

CRUZ, Marcia Terezinha J. O. Ritos, símbolos e práticas formativas: a Faculdade de Direito de Sergipe e sua Cultura Acadêmica (1950 - 1968). São Cristóvão-Sergipe: UFS, 2014 (Doutorado em Educação).

DANTAS, José Ibarê. A tutela militar em Sergipe, 1964/1984. Rio de Janeiro: Tempo Brasileiro, 1997.

DANTAS, José Ibarê. História de Sergipe: República (1889 - 2000). Rio de Janeiro: Tempo Brasileiro, 2004. 
DANTAS, José Ibarê. 0 domínio militar em Sergipe. [s.d]. Disponível em

<http://www.fundaj.gov.br/images/stories/observanordeste/observa_sergipe_01.pdf.> Acesso em 20.01.2013.

DANTAS, Maria José. FREITAS, Anamaria G. B. de. Intercâmbio epistolar e história da educação: possibilidades investigativas. Aracaju: Sergipe, 2014 (mimeo).

DAUPHIN, Cécile; POUBLAN, Danièle. Maneiras de escrever, maneiras de viver. Cartas familiares no século XIX. In: BASTOS, Maria Helena Câmara; CUNHA, Maria Teresa Santos; MIGNOT, Ana Chrystina Venâncio (Orgs.). Destinos das letras: história, educação e escrita epistolar. Passo Fundo (RS): Editora da UPF, 2002. p. 75-88.

FOUCAULT, Michel. A escrita de si. In: O que é um autor? Lisboa: Passagens. 1992. p. 129-160.

GOMES, Ângela de Castro (Org.). Escrita de si e escrita da História. Rio de Janeiro: Editora FGV, 2004.

MARCUSCHI, Luiz Antônio. Produção textual, análise de gêneros e compreensão. São Paulo: Parábola Editorial, 2008.

NASCIMENTO, Ester Fraga Vilas-Bôas Carvalho do. et al. Educação Superior em Sergipe 1991- 2004. In: RISTOFF, Dilvo; GIOLO, Jaime (Orgs.). Educação Superior Brasileira:19912004. Brasília: Instituto Nacional de Estudos e Pesquisas Educacionais Anísio Teixeira, 2006. p. 22-72.

OLIVEIRA, João Paulo Gama. Disciplinas, docentes e conteúdos: itinerários da história na Faculdade Católica de Filosofia de Sergipe (1951-1962). São Cristóvão: Sergipe, 2011. Dissertação (Mestrado em Educação). 